\title{
Romania: \\ The Kris Procedures. A Brief Incursion in the Roma Community-Based Dispute Management Mechanism
}

\author{
Christian-Radu CHEREJI \\ Ciprian SANDU
}

\begin{abstract}
Indigenous conflict management practices have seen a revival of scholarly interest in the last decades. Even if bias against them still exist in the academic and practitioners' environments, they have slowly conquered ground as mediation and other ADR methods gained track as viable alternatives to the modern justice system of courts, judges and lawyers. In this paper we focus on discovering how Roma communities (probably one of the most misunderstood and stereotyped ethnic group in Europe) deal with conflict ranging from insult and theft all the way

Christian-Radu CHEREJI

Director of Conflict Studies Center, College of Political, Administrative and Communication Sciences,

Babes-Bolyai University,

Cluj-Napoca, Romania

E-mail: chereji@fspac.ro

\section{Ciprian SANDU}

Mediator, Transylvanian Institute of Mediation Researcher, Conflict Studies Center Cluj-Napoca, Romania to kidnapping and murder. The Kris, as the traditional Roma court system is known, consists on a set of procedures that have strong similarities with both mediation and arbitration as known in the Western literature and practice, but with some notable particularities. The paper is based on interviews with krisinitori (peace judges in Romani language) and direct observation. It aims to unveil a system of practices based on rules and norms far away from the regular image of "uncivilized" and "lawless" the Roma hold in the mind of their European contemporaries.
\end{abstract}

E-mail: ciprian.sandu@fspac.ro

Conflict Studies Quarterly

Issue 24, July 2018, pp. 3-11

DOI:10.24193/csq.24.1

Published First Online: 05/07/2018
Keywords: Roma, Romani, Romanipen, disputes, conflict management, conflict resolution, indigenous practices, mediation, arbitration, facilitation, litigation, modern courts system, Kris, krisnitori, traditional justice, retributive justice, restorative justice 
The study of indigenous community conflict management practices has seen a resurgence in interest over the last couple of decades. With the trend in the West of looking for alternatives to the courts system of retributive justice, caused by high costs, huge backlogs and ineffective resolution of disputes, scholars have started to focus their attention on conflict and conflict management patterns across non-Western cultures (Augsburger, 1992; Zartmann, 2000; Chase, 2005, Weyrauch, 2001, to name but a few). Naturally, they draw on the vast anthropological research of previous eras which investigated the relationship between law, crime, customs and cultural norms(Leach, 1954; Malinowski, 1926; Evans-Pritchard 1940a and 1940b; and many, many others). Some advocates of mediation, facilitation and arbitration realized that these methods, of rather young interest and practice in the West, have remained mainstream in other parts of the world, surviving the onslaught of colonialism, failed or partial modernization and the last wave of globalization. Communities across Africa, Asia, Australia and Oceania, Americas and, indeed, Europe (Tsantiropoulos, 2008, 2013; Chereji, 2018), have conserved their traditional ways of dealing with conflict between their members and those methods have been proved time and cost effective. Not to mention their restorative/ integrative approach, so different from the retributive philosophy of Western justice.

Nonetheless, however refreshed the interest for studying conflict patterns and conflict management practices across cultures, there is still an immense work to do, vast areas of the world where indigenous mechanisms of conflict management are little investigated and even less understood. Of no little consequence is here the still largely held belief that "modern" mediation (i.e., mediation as practiced in the West, especially in the English language countries) is superior to those forms practiced in other parts of the world, the same as, some time ago, the Western justice system of courts, judges and lawyers was seen superior to justice systems existing in Africa, Asia or elsewhere, which were dismissed as "backward", "obsolete" and "based on superstitions". A belief that persists today, betrayed by expressions like "formal justice system" (when referring to the Western model of court litigation) as opposed to "informal practices" (when talking about indigenous community-based conflict management systems), expressions that pervade scholarly articles, field reports or research project proposals. Clearly the persistence of such a distorted view does not pave the ground for extended funding of projects dedicated to investigating and understanding how communities across the world deal and have dealt over time with dispute and crime.

There is not more evident an example of this bias than the case of Roma communities. Marginalized in most European countries where they live (and have lived for the last thousand years in some situations) because of their stubborn adherence to cultural norms distinct from the mainstream European ones, they are labelled "nomads", "dirty", "thieves", "kidnappers", "beggars" and so on. As usual, labelling tends to hide a far more complex reality. 
We are not going to deal with all the intricacies of Roma society, as our focus remains circumscribed to mechanisms of dispute management. It is enough to say that the political, social and economic changes of the last centuries have greatly altered the traditional Roma society. However, even switching from a transhumant to a sedentary way of life, there are communities that still respect the tradition and moral codes of conduct just as in the old times. Being marginalized and subjected to oppression for centuries, subjects of forced assimilation and discrimination, the Roma have developed their own survival strategies, strategies that make them different from other ethnicities.

The media often portray them as people without respect for the law or the values of modern European society. In Romania and elsewhere, tendentious reports in the media, generally qualifying the Roma as "criminals" and "uncivilized", allowed a significant part of the population to project all their grievances upon the Roma.

We decided to go beyond what is apparent and get deeper into the Roma world, to understand its ways and, most of all, to get a grasp of how these communities spread across many countries and cultures still keep to their ways of dealing with conflict among themselves. After a prolonged interaction with the traditional Roma we can say, despite the number of negative titles in the press, that the Roma are far from living beyond or outside the Law. Whether it is true that sometimes they don't abide by the laws of the countries they live (which can be safely said about many of the nationals of those countries anyway), they solidly observe the norms and customs inscribed in their own code, the Romanipen. Moreover, the evidence shows that Roma have their own justice system which works differently, but more effectively than the courts systems of their countries of residence.

Failure to comply with Roma customary values inevitably leads to the emergence of conflicts. Conflicts are solved internally, through the supreme court of the Roma, the Kris (translated as peace judgment), which has the role to reconcile parties and to solve conflicts arising from non-compliance with the Roma code of conduct. A note for fellow Romanian readers: in Romania we use a lot the word Stabor for the Kris, but this is an error. The word was invented during Ceausescu's period and does not exist in the vocabulary of the Romani language.

Returning to the Kris, the conflicts that are solved here range from disregarding the given word and the oath made, theft committed within the community or the bringing of a serious offense, disrespect for the pure-impure rules, stealing a girl, disrespect shown to an older person, adultery, insisting to look at a woman, uncovering the head by a woman, all the way to true blood feuds between families or rival clans and the extreme cases of murder. Under this system, the whole community is involved in the decisionmaking and conflict resolution processes, because the responsibility of carrying out any sanctions belongs to the whole group. We must not forget that each Roma community is 
formed by four to five clans or extended families, so it is somehow natural for the whole community to be involved due to the family ties with the parties involved in the conflict.

In short, the Kris means a gathering (in a circle around the judges who sit at a table) where facts are told by the parties, witnesses are listen and justice is decided through a verdict. As clearly expressed by our sources, the main goal is to reconcile and improve the situation (peace), rather than establishing who is right and who is guilty (justice). The Kris, from the point of view of conflict resolution literature, works mostly like a med-arb process with the particular color and flavor of Roma tradition influences.

The Kris is presided by highly experienced and respected neutrals known as krisinitori or peace judges. They havea role of more akin to a facilitator despite their appellation as "judges"- they act in a manner more similar to a mediator combined with an arbiter than a judge. The number of the judged must be impair (usually three or five) so that there is no chance for a tied verdict.

The krisinitor must be a person who knows the Roma's customs, practices and traditions very well, he must be impartial, a wise person, with a rich life experience, wealthy and who, most importantly, enjoys the respect of the community. The last condition (but not exclusively) has its roots in the hierarchy that defines the Roma collectivity. First of all, the Roma community is a patriarchal one. Secondly, there is a clear stratification of roles inside the Roma families which, in turn, influence the stratification of the Roma community. The head of the family is the male and he is the one who supports financially his family and the one who brings the luck for his family. As a short parenthesis, the oldest member of the family is so respected by the others that, even if his is very old or sick, the family will not leave him in a hospital or asylum because it would mean a great shame for them. Secondly, the Roma community has traditional leaders who were selected due to their good reputation. The entire Roma's conception about life is based around the notion of shame and respect. As one member of a Roma community told us "Without respect, you are nothing...respect is the characteristic of a true Roma" (personal communication, 2017, June). Due to this reasons, the patriarchate, the hierarchical stratification inside the Roma family and the Roma community, a top representative of the clan can't be held accountable for his actions by his inferiors on the social scale. This is why the judges (krisinitori) are top members of the community, both in terms of richness, respect and personal life. Meeting all these characteristics, the Roma judges can impose their verdicts to any member of the community.

As mentioned before, what happens during the Kris is consistent with the characteristics of the med-arb process. It begins with the opening statement of the judges who initiate the "trial" using a standard formula, the custom requiring a gradual, indirect introduction to the subject, discussions focusing at the beginning on general issues (weather, crops, etc.). Only slowly, deliberately, once the introduction has been exhausted, one of 
the judges presents to the assistance the motivation of the meeting, not before a last attempt to reconcile the parties amiably is made.

The meeting then continues with the judges hearing each side's story. The parties are encouraged to express their side of the story with a high level of details, facts and profs. This stage of the Kris is the same as in the case of mediation and arbitration where the parties take their time to tell their story. Also resembling these two procedures, the judges facilitate the story telling process by establishing and imposing of ground rules. The judges require the observance of conduit rules so that the parties can have a fluent exposition, without interruptions or a bad language. Also, acting as facilitators, the judges ask questions in order to help the parties tell the whole story and for both of them to understand the facts, the reasons and the interests. If there is the case, after the statements of the parties, the judges talk with witnesses for a better understanding of the situation.

The joint meeting format is used when the situation is not emotionally difficult. In the case where the conflict has been a violent one and there is wisdom in keeping the conflicting parties separated, the judges go to each party house and talk with them (the same as the caucus in mediation).

To preserve the fairness of the hearings and not to escalate the conflict even further, the judges are accompanied by each side's (trusted and not directly involved) family members so that they are witnesses for the correctness of each party statements and for the fair conduct of the judges. In this way, the parties are sure that the judges have not been corrupted by bribery by the oppositeparty. Here there can be perceived the great lengths by which judges go to be accountable and transparent. This is consistent with our research of other community-based dispute management mechanisms (Chereji \& Wratto, 2013, 2015) showing that they put much more emphasis on transparency and accountability then confidentiality, departing from the Western mantra of absolute confidentiality as a key feature of mediation and other ADR methods.

After the parties and the witnesses are heard, the judges ask the gathering if there is anyone who wants to say something regarding the conflict. If the answer is yes, they listen to them, if not, the judges retire in order to deliberate and establish the verdict. The verdict is issued based on the analysis of the facts and depositions in accordance to the Romanipen, customs and precedent. The verdict always includes a punishment, either moral or financial. The financial one is mostly in the form of fines. The moral ones are less used in our days and refers to the ostracization of the guilty party, temporary or permanently, from the community.

Due to the main goal of the process, peace and not necessarily justice, the verdict takes into account the social and economical status of the parties, the circumstances and the context of the deeds done, the prior behavior of the parties, their character and status. 
In the words of one krisinitor, "only God judges everyone, we try to bring you the peace" (personal communication, Roma krisinitor, December 6, 2017). When they announce the verdict, the judges appeal to all the oratorical art they have in order to convince the audience of the logic of reasoning, the motivation of the positive or negative approach of the accusations or the verdict ${ }^{1}$, in accordance with the principles of the Gypsy justice. The krisinitori strive to issue valuable judgments, showing the gathering that they have the ability to express themselves, their deductive perspicacity, experience, and, therefore, that they deserved the trust they have been invested. Being a society that promotes unconditionally respect to superiors on the hierarchical scale, the audience values the crafted words so that the oratory talent is a way, not at all insignificant, to gain respect, "to be respected, you must know how to talk to the Gypsies" (personal communication, Roma krisinitor, December 6, 2017).

The resemblance with the med-arb procedure is more visible regarding the final arrangements and closure of the Kris. The judges leave the parties time to negotiate their agreement, both before and after the verdict. If the parties reach their own agreement, they must bring it in front of the judges, because they are the only one who can impose it. If the parties don't have the ability or desire to reach their own solution, the verdict is issued by the judges, who turn arbiters at this time. What puts a lot of pressure on the judges to come up with a sound and wise verdict is the fact that the parties, if they consider it unfair or unwise (and are supported by the audience, hence the importance of logical and oratorical skills of the judges when presenting the verdict), can call for another Kris to be held. If the new Kris contradicts the previous verdict, that is a huge failure for the former judges and their reputation badly damaged.

One last thing regarding the outcome of the Kris relates to Romanipen, the moral code of the Roma people. Romanipen is the set of values or codes that Roma have to follow to be a true Roma, as they called themselves. These values are based on four principles (or elements): honor, good fortune, family (actually understood as belonging to the whole community) and cleanliness/purity. Failure to comply with these four principles will lead to a great shame and a bad reputation inside the Roma community. Romanipen

1 The Roma judges explain their verdict to both parties, telling them why one of them is going to receive apologies or an amount of money (the victim, for example) but also why they punish the other one with a fine or compensation. The reason for this is to show the parties that the judges listened their depositions and issued a fair verdict for both of them. Also, in some cases, the Roma judges will issue a verdict which is not fully fair for the parties but is efficient in ending the conflict. For example, one reputable Roma judge told us that sometimes he admits to a victim that she is entitled to a specific compensation but, due to the financial state of the other party, he must lower the demands. As he explained, in theory, the victim is losing some money he deserved; in practice, the conflict is ended and the guilty party will pay the compensation (even a smaller one) without the possibility for a new conflict to arise between them. 
is based around the notion of shame, same as the verdict of the judges (literally, some krisinitori told us that when they announce the verdict, basically, they came with the shame, meaning their verdict will shame the guilty side for his actions). The parties must respect the outcome of the Kris mostly due to the shame that would come up on them and their entire family if they will not comply with the decision of the judges. Moreover, failing to comply with the verdict means a greater conflict and a bigger punishment that the one issued before.

Central to the procedures of Kris, from initiation to closure, is the oath the parties and the witnesses must to take before, during and at the end of Kris. Performed in front of the audience, it has a sacred, infallible character and, as a result, "the Gypsy who sworn must always tell the truth" (personal communication, Roma community member, May $21,2016)$, otherwise it will turn into an extremely dangerous curse for the whole family of the one who swears shamefully. In a hypothetical situation in which a Gypsy stains the Gypsy oath in a lie, the community will later penalize him by marginalizing and abolishing his social status, both because of the lie, which is not forgotten and forgiven, as well as the curse that lies on the liar and his family.

The oath of the Gypsy is carried out according to predetermined rules which imply the use of ritual elements meant to strengthen the truth and attract the forces of evil in the case of a lie. This is equivalent to a certificate guaranteeing the sincerity of the active participants in the process. The majority of oaths center on the family. As mentioned above, one of the four pillars of Romanipen is family. Having so much importance for the Roma, this kind of oath is a strong guarantee that the one who take the oath is telling the truth because "on the family you can't lie". Lying about something when your oath was on a member of the family is a sign of a bad omen and for the Roma, who are a very superstitious community, this function like a deterrent. A special type of oath is centered on the children and it is considered the ultimate guarantee for telling the truth ("I swear on my chlid's eyes", May my children to die if I lie").

A few words in the end about the role of women in the Kris. In the old ages, due to the fact that the Roma society has ever been solidly patriarchal, the women were not allowed to participate to the Kris, even if they were the victims. If a woman was the victim of a theft, rape or another situation, her husband was the one who brought the case in front of the judges. His wife had only a secondary role in the procedure, mostly assisting her husband during the deposition phase. In the case of widows or orphans, their uncle was responsible for bringing the case in front of the judges. If the uncle was also missing, the woman could be helped by any other male relative or, in the unfortunate case when she was all alone, any male member of the community.

Nowadays, women have a bigger role in the Kris, they can participate more actively and, even if there is a lot of controversy and opposition regarding this issue, some of them even became krisinitori. 
Women have an important role in facilitating the agreement. It is well known that the "Gypsy women are like fire" (even if this is more a stereotype than a certain fact) and can influence their husbands to accept the verdict of the Kris or the offer of the other party. For this reason, in many situations, judges rely on wives of the disputing parties to facilitate an agreement or make sure they accept and observe the verdict.

\section{Instead of conclusions}

Our study is just a brief incursion into the complex world of Roma communities and their own mechanisms designed to deal with conflicts. Far from being the "lawless" society their co-nationals assume, the Roma show a consistent adherence to a strict code of conduct based on their customs and cultural norms. This is Romanipen, the way to be a true Roma. Based on four major pillars, Romanipen is centered around the notion of shame and community as a means to preserve the Roma identity. The principles of Romanipen are also used in order to deliver justice in the community. This consistency is shown in the fact that, even if a Roma person is convicted for crime or misbehavior by a "formal" court of justice, she or he still has to undergo through a Kris to settle the conflict with the aggrieved party, no matter how severe is the verdict of the "formal" court. If the perpetrator fails to go through the Kris, the conflict persists and can lead to retaliation even after she/he has spent a long time in jail. Only the Kris can definitively put an end to a conflict. More importantly, for the majority of the Roma people, the Kris is the only court they recognize. Being conducted with respect to the principles of the Romanipen, the Kris is performed in front of the community by peace judges (krisinitori) who are highly respected members of the Roma community and who have the responsibility to settle a conflict situation. Accordingly to their name (in the Romani language, krisinitor means the one who brings the peace), these judges are focused on the notion of peace and not specifically on the notion of fairness. For this, the Roma judges will adjust their role and technique depending on each conflict. Sometimes, they will act as facilitators of the negotiation between the parties, being the ones who will communicate offers and intermediate the final agreement. In other cases, they will act as arbitrators, listening to the parties and coming up with a decision. Sometimes, they will use the med-arb conflict resolution hybrid, assisting the parties and facilitating their agreement but giving a solution if the parties don't have the ability to reach their own.

Also, contrary to the opinion of the majority of their co-nationals, Roma communities do not abide and hide crime like theft, rape or murder (as it has been largely speculated in the press). The fact that they prefer to deal with these crimes inside their own communities and refrain from reporting them to official law enforcement organizations does not imply the Roma society takes crime lightly, but rather the fact that they consider their own norms and procedures far more fair and effective than those used by police and courts of justice. Given the bias against them held by many members of these in- 
stitutions, as by the majority of their co-nationals which inform official institutional cultures across Europe and elsewhere, they might as well be right.

\section{References}

1. Augsburger, D. W. (1992). Conflict Mediation Across Cultures: Pathways and Patterns. Westminster: John Knox Press.

2. Chase, O. G. (2005). Law, Culture, and Ritual: Disputing Systems in Cross-Cultural Context. New York: New York University Press.

3. Chereji, C. R., \& Wratto, C. (2013). West Africa. A Comparative Study of Traditional Conflict Resolution Methods in Liberia and Ghana. Conflict Studies Quarterly, 5, 3-18.

4. Chereji, C. R., \& Wratto, C. (2015). Aspects of Traditional Conflict Management Practices among the Ogoni of Nigeria. Conflict Studies Quarterly, 10, 56-68.

5. Chereji, C. R. (2018, January). Mediating Blood Feuds in Cretan Mountains. Mediate. com. Retrieved from https://www.mediate.com/articles/raduc1feud.cfm.

6. Evans-Pritchard, E. E. (1940a). The Nuer: A Description of the Modes of Livelihood and Political Institutions of a Nilotic People. Oxford: Clarendon Press.

7. Evans-Pritchard, E. E. (1940b). The Nuer of the Southern Sudan. In M. Fortes and E. E. Evans-Pritchard (Eds.), African Political Systems (pp. 272-296). London: Oxford University Press.

8. Leach, E. R. (1954) Political Systems of Highland Burma: A Study of Kachin Social Structure. London: Bell and Sons.

9. Malinowski, B. (1926). Crime and custom in savage society. New York: Harcourt, Brace \& Co.

10. Tsantiropoulos, A. (2008). Collective Memory and Blood Feud: The Case of Mountainous Crete. Crimes and Misdemeanours: Deviance and the Law in Historical Perspective, 2(1), 60-80.

11. Tsantiropoulos, A. (2013). Crime and Culpability in the Community, the Newspapers and the Courts.In J. Rowbotham, M. Muravyeva and D. Nash (Eds.), Shame, Blame and Culpability. Crime and Violence in the Modern State (pp. 199-214). New York: Routledge.

12. Weyrauch, W. O. (2001) Gypsy Law: Romani Legal Traditions and Culture. London: University of California Press.

13. Zartman, I. W. (2000). Traditional Cures for Modern Conflicts: African Conflict 'Medicine'. Boulder, CO: Lynne Rienner. 